\title{
PENGEMBANGAN E-MODUL PEMBELAJARAN INTERAKTIF BERBASIS FLIP PDF CORPORATE EDITION PADA MATA KULIAH MANAJEMEN DIKLAT
}

\author{
ZINNURAIN \\ Teknologi Pendidikan Fakultas Ilmu Pendidikan dan Psikologi \\ Universitas Pendidikan Mandalika \\ zinnurain@undikma.ac.id
}

\begin{abstract}
ABSTRAK
Penelitian ini bertujuan untuk: (1) mengembangkan dan menghasilkan E-modul pembelajaran interaktif berbasis Flip PDF Corporate Edition pada mata kuliah Manajemen Diklat yang layak digunakan berdasarkan aspek materi, desain dan media. (2) mengetahui efektifitas penggunakan e-modul yang digunakan dalam pembelajaran. Penelitian ini merupakan penelitian Research and Development (R\&D) dengan menggunakan model pengembangan Borg and Gall. Subjek dalam penelitian ini adalah Mahasiswa Semester III Program Studi Teknologi Pendidikan Fakultas Ilmu Pendidikan dan Psikologi (FIPP) UNDIKMA. Uji validitas $e$-modul dilakukan oleh ahli materi, ahli desain, dan ahli media. Hasil penelitian pengembangan ini menunjukkan produk yang dikembangkan memenuhi kriteria validasi ahli materi mencapai $92 \%$ dengan kategori sangat valid, ahli desain pembelajaran mencapai $83 \%$ dengan kategori valid, ahli media mencapai $87 \%$ dengan kategori valid dan $86 \%$ persentase untuk efektifitas penggunaan media. Implikasi dari hasil penelitian ini adalah dapat membangun, memicu, memperkuat minat mahasiswa untuk belajar secara mandiri dan proses pembelajaran lebih efektivitas, efesiensi sehingga terjadi peningkatan kualitas pembelajaran.
\end{abstract}

Kata Kunci: e-modul pembelajaran interaktif, flip pdf corporate edition, desain diklat

\section{PENDAHULUAN}

Dunia saat ini sedang menghadapi perubahan industri ke-4 atau yang dikenal dengan Industri 4.0. Era Revolusi Industri keempat ini diwarnai oleh kecerdasan buatan (artificial intelligence), super komputer, rekayasa genetika, teknologi nano, mobil otomatis, dan inovasi. Perubahan tersebut terjadi dalam kecepatan eksponensial yang akan berdampak terhadap ekonomi, industri, pemerintahan, dan politik (Satya, 2018). Begitu juga pada perkembangannya, manusia adalah makluk cerdas yang selalu meningkatkan kemampuannya untuk memudahkan setiap kegiatannya. Segala alat dicoba dan digunakan untuk mencapai efisisensi dan efektifitas setiap tindakan yang dilakukannya, berbagai percobaan dilakukan agar dapat menghasilkan jumlah efiisensi yang besar dengan tenaga yang seminimal mungkin.

Manusia menggunakan teknologi karena memiliki akal. Dengan akalnya manusia ingin keluar dari masalah, ingin hidup lebih baik, lebih aman, dan sebagainya. Perkembangan teknologi terjadi karena seseorang menggunakan akalnya untuk menyelesaikan setiap masalah yang dihadapinya. Kemajuan teknologi adalah sesuatu yang tidak bisa dihindari, karena kemajuan teknologi akan berjalan sesuai dengan kemajuan ilmu pengetahuan. Setiap inovasi diciptakan untuk memberikan manfaat positif bagi kehidupan manusia. Teknologi juga memberikan banyak kemudahan, serta sebagai cara baru dalam melakukan aktivitas manusia. Manusia juga sudah menikmati banyak manfaat yang dibawa oleh inovasi dan kreatifitas teknologi yang telah dihasilkan dalam dekade terakhir ini (Tayibnapis, 2019). Pada era globalisasi saat ini, penguasaan teknologi menjadi prestise dan indikator kemajuan suatu negara. Negara dikatakan maju jika memiliki tingkat penguasaan teknologi tinggi (high technology), sedangkan negara-negara yang tidak bisa beradaptasi dengan kemajuan teknologi sering disebut sebagai negara gagal (failed country) (Ngafifi, dkk, 2014).

Perkembangan teknologi dalam kehidupan dimulai dari proses sederhana dalam kehidupan sehari-hari samapai pada tingkat pemenuhan kepuasan sebagai individu dan makluk sosial. Dari masa ke masa keamajuan teknologi terus berkembang, mulai dari era teknologi pertanian, era teknologi industri, era teknologi informasi, dan era teknologi komunikasi dan 
informasi. Perkembangan ini membawa berbagai dampak dalam kehidupan bermasayarakat, berbangsa dan bernegara, setiap individu tertarik untuk mengunakan dan memanfaatkan setiap perkembangan ini (Danuri, 2019). Begitu juga dalam proses pembelajaran, perkembangan Teknologi Inforomasi dan Komputer (TIK) merambah cepat dan signifikan.

Dalam dunia pendidikan, TIK telah menjadi bagian dari perubahan secara radikal modamoda penyampaian informasi pendidikan, TIK dapat memainkan peran kritis dalam mengkonstruksi pengetahuan dengan memungkinkan membuat, mengelola, dan berbagi pengetahuan (Susanti, dkk, 2016). Peningkatan kualitas pembelajaran di perguruan tinggi harus sejalan dengan perkembangan teknologi komunikasi dan informasi yang sedang berkembang luas di masyarakat. Berbagai strategi dan salah satu alternatif yang dapat dilakukan adalah dengan melakukan pengembangan bahan ajar. Dimana pengembangan bahan ajar dilakukan oleh seorang dosen untuk memecahkan permasalahan pembelajaran dengan memperhatikan sasaran atau mahasiswa dan juga menyesuaikan dengan kompetensi yang harus dicapai. Salah satu cara untuk merealisasikannya adalah dengan mengintegrasikan bahan ajar dengan teknologi sehingga tercipta suatu bahan ajar yang mudah diakses dan memenuhi kriteria tersebut (Linda, 2018). Salah satu bentuk bahan ajar yang dapat dikembangkan adalah modul berbasis digital atau yang dikenal dengan e-modul.

Pengertian modul menurut Association of Educational Communication and Technology (AECT) adalah sebagai berikut: (1) modul pembelajaran merupakan suatu kumpulan pengalaman belajar (biasanya dalam bentuk belajar sendiri) yang dirancang atau dirakit untuk mencapai sekelompok tujuan khusus yang saling berkaitan; biasanya terdiri atas beberapa jam atau beberapa minggu. Modul ini disebut bahan ajaran kecil jikalau satuan kreditnya ditentukan (Heinich, 2002: 53).

Adapun Modul elektronik (e-modul) merupakan pengembangan modul cetak dalam bentuk digital yang banyak mengadaptasi dari modul cetak dan bisa diakses melalui perangkat (Sugihartini, dkk 2017). E-modul merupakan modul dengan format elektronik yang dijalankan dengan komputer. E-modul dapat menampilkan teks, gambar, animasi, dan video melalui piranti elektronik berupa komputer. Kemajuan teknologi juga telah memungkinkan e-modul ditampilkan melalui smartphone.

Kelebihan e-modul dibandingkan modul konvensional antara lain: a) e-modul dinilai lebih menarik karena dilengkapi gambar, video dan sebagainya, b) lebih interaktif karena mahasiswa dapat melakukan evaluasi secara mandiri, c) bebas kertas karena bentuknya elektronik, d) multiplatform karena dapat digunakan melalui komputer, laptop dan handphone (Nisa, dkk, 2020). Kelebihan lainnya e-modul juga dapat mengurangi penggunaan kertas dalam proses pembelajarannya. Sebuah e-modul disusun secara sistematis dengan bahasa yang dapat menyesuaikan dengan kemampuan mahasiswa. Sehingga tidak membingungkan mahasiswa dalam memahami.

E-modul juga merupakan bahan ajar yang dapat membantu mahasiswa mengukur dan mengontrol kemampuan dan intensitas belajarnya. Penggunaan modul tidak dibatasi tempat dan waktu, karena tergantung kesanggupan mahasiswa dalam menggunakan modul. Dengan demikian e-modul yang dikembangkan dapat digunakan kapan saja dan dimana saja menggunakan smartphone yang rata-rata telah dimiliki mahasiswa di era teknologi ini. Sehingga keterbatasan bahan ajar pada saat guru menjelaskan dapat terbantu serta pada saat praktikum mahasiswa sudah memahami apa yang akan dikerjakan karena mahasiswa sudah mempelajarinya terlebih dahulu (Laili, 2019).

Pada proses pembelajaran mata kuliah Desain Diklat Semester III Ganjil periode 2020/2021 di program studi teknologi pendidikan FIPP Universitas Pendidikan Mandalika (UNDIKMA), sudah menggunakan pembelajaran berbasis online dikarenakan penyesuaian kondisi di tengah Pandemi Covid-19. Oleh sebab itu perlu adanya suatu pengembangan bahan ajar yang mampu menunjang pembelajaran jarak jauh berbasis online yang digunakan agar kegiatan perkuliahan pada mata kuliah Desain Diklat tidak mengalami kendala dalam penyerapan materi yang dialami oleh mahasiswa. Oleh karena itu, peneliti melakukan 
pengembangan bahan ajar berupa e-modul pembelajaran interaktif sebagai bentuk alternative pembelajaran online yang bisa digunakan secara optimal baik oleh dosen, maupun mahasiswa. Pengembangan e-modul ini merupakan langkah untuk memastikan keaktifan mahasiswa serta menjamin terbentuknya pembelajaran berbasis mahasiswa (Student-Center Learning). Pada situasi pandemic Covid-19, bisa dikatakan bahwa modul yang tepat dalam proses pembelajaran adalah modulelektronik atau e-modul. E-modul merupakan modul elektronik yang aksesnyadilakukan melalui alat elektronik seperti komputer, handphone, tablet. E-modul dinilai lebih inovatif karena menyajikan materi secara lengkap, apalagi saat ini mahasiswa lebih sering membuka handphone daripada buku. Dengan e-modul mahasiswa bisa menggunakan handphonenya untuk belajar (Susanti, dkk, 2021).

Penelitian ini juga dilatarbelakangi oleh fakta bahwa pada mata kuliah Desain Diklat belum pernah dilakukan pengembangan modul berbasis elektronik atau e-modul pembelajaran interaktif oleh peneliti sendiri selaku dosen pengampu pada mata kuliah tersebut. Adanya kondisi pandemi Covid-19 yang terjadi menjadi dasar ide adaptasi atau penyesuaian metode pembelajaran menjadi pembelajarn berbasis online. Adapun pengembangan e-modul pembelajaran interaktif untuk mata kuliah Desain Diklat untuk Mahasiswa Semester III Ganjil periode 2020/2021 menjadi alternative pembelajaran jarak jauh agar mampu menjamin bahwa proses perkuliahan bisa dilakukan secara optimal.

Adapun e-modul pembelajaran interaktif yang dikembangkan adalah berbasis Flip Pdf Corprate Edition. Flip Pdf Corporate Edition merupakan salah satu aplikasi pengembangan Pdf yang bisa diakses secara online maupun offline yang berisi, teks, audio, video, gambar, dan sebagainya. Modul elektronik (e-modul) dapat menjadi sumber informasi yang interaktif karena menyajikan informasi secara dinamis dengan dukungan dari multimedia seperti gambar, video, dan simulasi (Irwansyah, dkk, 2017). Penggunaan multimedia dalam modul elektronik dapat memfasilitasi proses pembelajaran yang lebih mudah dipahami, efektif, dan menyenangkan karena multimedia pendukung tersebut dapat menyajikan visualisasi yang lebih jelas dari materi pembelajaran untuk membantu pemahaman mahasiswa (Dori, 2013). Karakter e-modul yang mudah, praktis, efektif dan efisien akan mampu menghadirkan pembelajaran mandiri yang dirasakan oleh Mahasiswa (Ramdhani, dkk, 2015).

\section{METODE PENELITIAN}

Penelitian ini merupakan Research and Development (R\&D) dengan menggunakan model pengembangan Borg and Gall yang meliputi langkah-langkah (1); penelitian pendahuluan (persiapan, survey pendalaman, analisis kebutuhan), (2); perencanaan pengembangan produk (pengumpulan data, identifikasi produk yang dikembangkan), (3); validasi dan revisi produk (telaah pakar, uji coba kelompok kecil, uji coba kelompok besar), (4); implementasi produk (perencanaan, persiapan, pelaksanaan, observasi, evaluasi). Metode penelitian pengembangan adalah metode penelitian yang digunakan untuk menghasilkan suatu produk, serta menguji bagaimana keefektifan suatu produk tersebut (Sugiyono, 2015).

Penelitian ini dilaksanakan untuk mengembangkan e-modul pembelajaran interaktif berbasis Flip PDF Corporate Edition pada mata kuliah Manajemen Diklat yang layak digunakan berdasarkan aspek materi, desain dan media. Penelitian ini dilakukan pada Program Studi Teknologi Pendidikan Fakultas Ilmu Pendidikan dan Psikologi Universitas Pendidikan Mandalika. Subjek dalam penelitian ini adalah mahasiswa program studi teknologi pendidikan FIPP UNDIKMA semester III yang berjumlah 30 orang. Penelitian ini dilakukan selama 1 semester yakni September 2020-Januari 2021.

Pada angket validasi ahli media, terdapat beberapa aspek yang dinilai dalam e-modul berbasis Flip PDF Corporate yang dikembangkan peneliti, antara lain aspek fisik/tampilan, pendahuluan, pemanfaatan, tugas/evaluasi serta rangkuman. Masing-masing aspek memiliki beberapa kriteria atau indikator. Pada angket validasi ahli materi, terdapat beberapa aspek yang dinilai dalam e-modul berbasis Flip PDF Corporate yang dikembangkan peneliti, antar lain 
aspek pendahuluan, pembelajaran, isi, tugas/evaluasi, rangkuman. Masing-masing aspek juga memiliki beberapa kriteria atau indicator.

Tabel 1. Kriteria Hasil Validasi

\begin{tabular}{cc}
\hline Skor dalam Presentase & Kriteria Validasi \\
$81 \%-100 \%$ & Sangat Layak \\
$61 \%-80 \%$ & Layak \\
$41 \%-60 \%$ & Cukup Layak \\
$21 \%-40 \%$ & Kurang Layak \\
$<20 \%$ & Tidak Layak \\
\hline
\end{tabular}

\section{HASIL DAN PEMBAHASAN}

Validasi ahli materi pada e-modul pembelajaran interaktif yang dikembangkan oleh satu ahli materi yaitu Dr. Zul Anwar, M.Pd yang merupakan dosen Program Studi Teknologi Pendidikan Universitas Pendidikan Mandalika. Penilaian dilakukan untuk meningkatkan kualitas isi materi dari E-modul interaktif untuk mahasiswa semester III pada semester ganjil 2020/2021. Hasil validasi terhadap komponen-komponen pada kualitas materi media pembelajaran E-modul apat dilihat pada gambar 1 berikut:

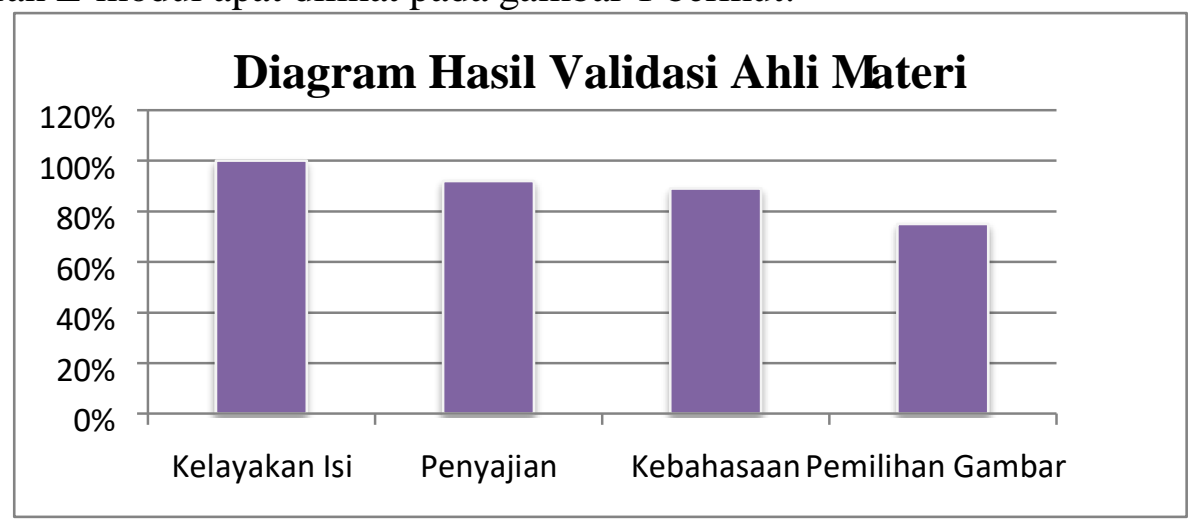

Gambar 1. Hasil Validasi Ahli Materi

Berdasarkan data hasil validasi ahli materi diatas dapat dilihat bahwa kelayakan isi, penyajian, kebahasaan, dan pemilihan gambar pada E-modul pembelajaran interaktif berbasis Flip PDF Corporate Edition secara umum masuk dalam kategori "Sangat Layak" dengan persentase $92 \%$.

Validasi desain pembelajaran pada E-modul pembelajaran interaktif berbasis Flip PDF Corporate Edition yang dikembangkan dilakukan oleh ahli yaitu Dr. Hadi Gunawan Sakti, S.Pd., M.Pd. yang merupakan dosen Program Studi Teknologi Pendidikan Universitas Pendidikan Mandalika. Hasil validasi berupa skor penilaian yang berkaitan dengan bidang desain pembelajaran diantaranya pendekatan pembelajaran, kebenaran konsep, kedalaman konsep, kesesuaian konsep, kegiatan pembelajaran, kegiatan percobaan, keterlaksanaan, penilaian, isi, visualisasi, dan kejelasan kalimat yang termasuk kualitas tampilan media pembelajaran yang dapat dilihat pada gambar 2 berikut: 


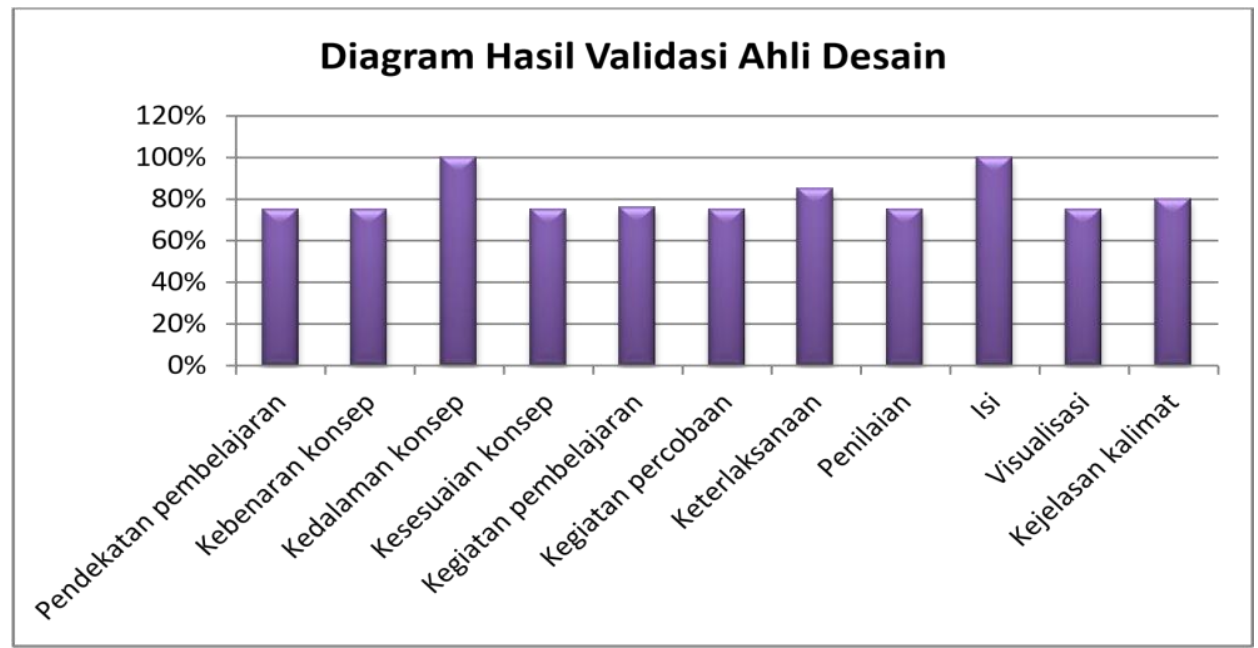

Gambar 2. Hasil Validasi Ahli Desain Pembelajaran

Berdasarkan data hasil validasi ahli desain pembelajaran sesuai pada tabel diatas dapat dilihat bahwa pendekatan pembelajaran, kebenaran konsep, kedalaman konsep, kesesuaian konsep, kegiatan pembelajaran, kegiatan percobaan, keterlaksanaan, penilaian, isi, visualisasi, dan kejelasan kalimat secara umum dalam kategori "Layak" dengan persentase $83 \%$.

Validasi media pada E-modul pembelajaran interaktif berbasis Flip PDF Corporate Edition yang dikembangkan dilakukan oleh ahli yaitu Dr. Agus Jayadi, M.Pd yang merupakan dosen Program Studi Teknologi Pendidikan Universitas Pendidikan Mandalika. Pada proses validasi dilakukan terkait desain layout/tata letak, teks/typografi, image, kemasan. Penggunaan, navigasi, dan interactive link. Adapun hasil validasi pada kualitas media dari E- Modul pembelajaran interaktif berbasis Flip PDF Corporate Edition dapat dilihat pada gambar 3 sebagai berikut:

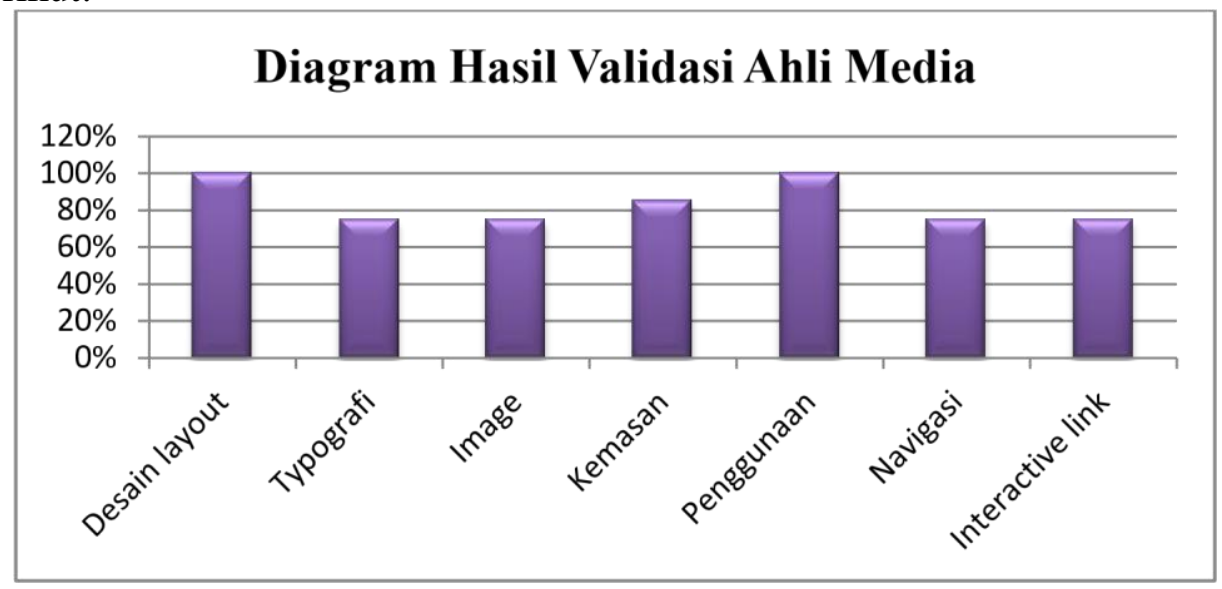

Gambar 3. Hasil Validasi oleh Ahli Media

Berdasarkan data hasil validasi ahli media sesuai pada Diagram di atas dapat dilihat bahwa tampilan desain layout/tata letak, teks/typografi, image, kemasan, navigasi, dan interactive link secara umum dalam kategori "Layak" dengan persentase $87 \%$.

Uji coba kecil dilakukan di program studi Teknologi Pendidikan. Uji coba kecil dilakukan pada 3 orang, yaitu mahasiswa dari kelas B. Tujuan dari uji coba kecil ini dilakukan untuk mengidentifikasi kekurangan produk dan persepsi terhadap E- Modul pembelajaran interaktif berbasis Flip PDF Corporate Edition yang telah dikembangkan setelah divalidasi oleh tim ahli. Setelah dilakukan uji coba kecil, maka peneliti melakukan revisi E-Modul pembelajaran interaktif berbasis Flip PDF Corporate Edition berdasarkan masukan yang telah diberikan. Hasil penilaian mahasiswa terhadap E- Modul pembelajaran interaktif berbasis Flip PDF Corporate Edition yang telah dikembangkan dapat dilihat pada tabel 2 berikut: 
Tabel 2. Hasil Persentase Kelayakan pada Uji Coba Kecil

\begin{tabular}{|c|c|c|c|}
\hline Nama & Skor Total & Skor Maksimal & Persentase \\
\hline AS & 50 & 80 & $63 \%$ \\
\hline MS & 51 & 80 & $64 \%$ \\
\hline RW & 50 & 80 & $63 \%$ \\
\hline Total & 151 & 240 & \\
\hline Persentase total & & & $63 \%$ \\
\hline Keterangan & & & Cukup layak \\
\hline
\end{tabular}

Persentase kelayakan terhadap E-Modul pembelajaran interaktif berbasis Flip PDF Corporate Edition pada saat dilakukan uji coba kecil dapat dilihat pada tabel 2 di atas bahwa e-modul di kategorikan "Cukup layak" dengan persentase 63\%.

Penilaian dilakukan oleh 10 orang mahasiswa kelas B dengan tujuan untuk mengetahui respon mahasiswa terhadap kelayakan E-Modul pembelajaran interaktif berbasis Flip PDF Corporate Edition yang dikembangkan. Hasil respon mahasiswa pada saat uji coba sedang terhadap E-Modul pembelajaran interaktif berbasis Flip PDF Corporate Edition yang telah dikembangkan dapat dilihat pada tabel 3 berikut:

Tabel 3. Hasil Persentase Kelayakan Media pada Uji Coba Sedang

\begin{tabular}{|c|c|c|c|}
\hline Nama & Skor Total & Skor Maksimal & Persentase \\
\hline SW & 52 & 80 & $65 \%$ \\
\hline ML & 59 & 80 & $74 \%$ \\
\hline $\mathrm{IH}$ & 55 & 80 & $69 \%$ \\
\hline MK & 48 & 80 & $60 \%$ \\
\hline NP & 53 & 80 & $66 \%$ \\
\hline RL & 57 & 80 & $71 \%$ \\
\hline RW & 53 & 80 & $66 \%$ \\
\hline SH & 56 & 80 & $70 \%$ \\
\hline IK & 50 & 80 & $63 \%$ \\
\hline BG & 48 & 80 & $60 \%$ \\
\hline Total & 531 & 800 & \\
\hline Persentase total & & & $66 \%$ \\
\hline Keterangan & & & Cukup layak \\
\hline
\end{tabular}

Persentase kelayakan terhadap E-Modul pembelajaran interaktif berbasis Flip PDF Corporate Edition pada saat melakukan uji coba sedang dapat dilihat pada tabel 3 dikategorikan "Cukup layak" dengan persentase 66\%.

Uji coba besar dilakukan dikelas B dengan jumlah mahasiswa 24 orang. Hasil respon mahasiswa pada saat uji coba sedang terhadap E-Modul pembelajaran interaktif berbasis Flip PDF Corporate Edition yang telah dikembangkan dapat dilihat pada tabel 3 berikut: 


\begin{tabular}{|c|c|c|c|}
\hline Nama & Skor Total & Skor Maksimal & Persentase \\
\hline ES & 52 & 80 & $65 \%$ \\
\hline PL & 52 & 80 & $65 \%$ \\
\hline NM & 58 & 80 & $73 \%$ \\
\hline $\mathrm{NH}$ & 46 & 80 & $58 \%$ \\
\hline SS & 52 & 80 & $65 \%$ \\
\hline ZIM & 49 & 80 & $61 \%$ \\
\hline $\mathrm{ABL}$ & 55 & 80 & $69 \%$ \\
\hline BIR & 52 & 80 & $65 \%$ \\
\hline RA & 51 & 80 & $64 \%$ \\
\hline HR & 46 & 80 & $58 \%$ \\
\hline NA & 45 & 80 & $56 \%$ \\
\hline SS & 48 & 80 & $60 \%$ \\
\hline FW & 48 & 80 & $60 \%$ \\
\hline FR & 48 & 80 & $60 \%$ \\
\hline MT & 48 & 80 & $60 \%$ \\
\hline NS & 51 & 80 & $64 \%$ \\
\hline YP & 51 & 80 & $64 \%$ \\
\hline YH & 57 & 80 & $71 \%$ \\
\hline $\mathrm{AG}$ & 53 & 80 & $66 \%$ \\
\hline AP & 56 & 80 & $70 \%$ \\
\hline ARP & 52 & 80 & $65 \%$ \\
\hline DG & 51 & 80 & $64 \%$ \\
\hline IJ & 47 & 80 & $59 \%$ \\
\hline RA & 48 & 80 & $60 \%$ \\
\hline Total & 1216 & 1920 & \\
\hline Persentase total & & & $63 \%$ \\
\hline Keterangan & & & Cukup layak \\
\hline
\end{tabular}

Persentase kelayakan terhadap E-Modul pembelajaran interaktif berbasis Flip PDF Corporate Edition pada saat melakukan uji coba besar dapat dilihat pada tabel 4 di atas bahwa media dikategorikan "Cukup layak" dengan persentase 63\%.

Tabel 5. Rangkuman Nilai Rata-rata Pretest dan Posttest

\begin{tabular}{cccc}
\hline Sumber Data & $\begin{array}{c}\text { Nilai Rata-rata } \\
\text { pretest }\end{array}$ & $\begin{array}{c}\text { Nilai Rata-rata } \\
\text { Posttest }\end{array}$ & Selisih \\
\hline Mahasiswa Kelas A (30 orang) & 61 & 86 & 25 \\
\hline
\end{tabular}

Berdasarkan tabel di atas dapat disimpulkan bahwa pembelajaran mata kuliah Desain Diklat E-Modul pembelajaran interaktif berbasis Flip PDF Corporate Edition dapat meningkatkan hasil belajar mahasiswa.

\section{KESIMPULAN}

E-Modul pembelajaran interaktif berbasis Flip PDF Corporate Edition yang dikembangkan telah divalidasi dan memenuhi kriteria media pembelajaran yang baik dan layak untuk digunakan dalam pembelajaran mata kuliah Desain Diklat di program studi teknologi pendidikan dimana $92 \%$ validasi oleh ahli materi, $83 \%$ validasi oleh ahli desain pembelajaran, 
dan $87 \%$ validasi oleh ahli media. Sedangkan kelayakan dari uji coba masing-masing berkisar $63 \%$ untuk uji coba kecil, 66\% untuk uji coba sedang, dan 63\% untuk uji coba besar. E-Modul pembelajaran interaktif berbasis Flip PDF Corporate Edition yang dikembangkan sudah efektif digunakan untuk meningkatkan hasil belajar mahasiswa dalam proses pembelajaran. Hal ini dapat dilihat dari analisis hasil belajar mahasiswa dengan menggunakan E-Modul pembelajaran interaktif berbasis Flip PDF Corporate Edition lebih efisien, dimana diperoleh nilai posttest lebih besar dibanding pretest.

\section{DAFTAR PUSTAKA}

Danuri, M. (2019). Perkembangan dan transformasi teknologi digital. INFOKAM, 15(2).

Heinich, R. et al. (2002). Instructional Media and Technology for Learning, 7th edition. New Jersey: Prentice Hall, Inc.

Irwansyah, F. S., Lubab, I., Farida, I., \& Ramdhani, M. A. (2017, September). Designing interactive electronic module in chemistry lessons. In Journal of Physics: Conference Series (Vol. 895, No. 1, p. 012009). IOP Publishing.

Laili, I. (2019). Efektivitas Pengembangan E-Modul Project Based Learning Pada Mata Pelajaran Instalasi Motor Listrik. Jurnal Imiah Pendidikan Dan Pembelajaran, 3(3), 306-315.

Linda, R. (2018). Interactive E-Module Development through Chemistry Magazine on Kvisoft Flipbook Maker Application for Chemistry Learning in Second Semester at Second Grade Senior High School. Journal of Science Learning, 1(2), 21-25.

Ngafifi, M. (2014). Kemajuan teknologi dan pola hidup manusia dalam perspektif sosial budaya. Jurnal Pembangunan Pendidikan: Fondasi dan Aplikasi, 2(1).

Nisa, H. A., Mujib, M., \& Putra, R. W. Y. (2020). Efektivitas E-Modul dengan Flip Pdf Professional Berbasis Gamifikasi Terhadap Siswa SMP. Jurnal Pendidikan Matematika Raflesia, 5(2), 13-25.

Ramdhani, M. A., \& Muhammadiyah, H. (2015). The criteria of learning media selection for character education in higher education.

Satya, Venti Eka. "Strategi Indonesia menghadapi industri 4.0." Info Singkat 10.9 (2018): 1924.

Susanti, Baiq Hana, and Fransisca S. Sumargo. "Pengembangan dan Implementasi Program Perkuliahan Vertebrata Berbasis Learning Object dengan Sistem E-Learning di Program Studi Pendidikan Biologi FITK UIN Jakarta." (2016).

Susanti, E. D., \& Sholihah, U. (2021). PENGEMBANGAN E-MODUL BERBASIS FLIP PDF CORPORATE PADA MATERI LUAS DAN VOLUME BOLA. RANGE: Jurnal Pendidikan Matematika, 3(1), 37-46.

Tayibnapis, Ahmad Zafrullah, Lucia Endang Wuryaningsih, and Radita Gora. "Pentingnya Inovasi dan Kreatifitas Era Teknologi Digital." (2019): 532-539. 